\title{
ACTIVIDAD ANTIBACTERIANA, DEGRADACIÓN HIDROLÍTICA Y MICROBIANA Y CITOTOXICIDAD IN VITRO DE POLIURETANOS SINTETIZADOS CON POLIOLES DERIVADOS DEL ACEITE DE HIGUERILLA
}

\author{
Yomaira L. Uscategui, Luis E. Díaz y Manuel F. Valero* \\ Doctorado en Biociencias, Universidad de La Sabana, Campus Universitario del Puente del Común, Autopista Norte de Bogotá, \\ D.C. Chía, Cundinamarca, Colombia
}

Recebido em 16/05/2016; aceito em 12/09/2016; publicado na web em 29/09/2016

\begin{abstract}
ANTIBACTERIAL ACTIVITY, HYDROLYTIC AND MICROBIAL DEGRADATION AND in vitro CYTOTOXICITY OF POLYURETHANE SYNTHESIZED WITH POLYOLS FROM CASTOR OIL DERIVATIVES. Biological activities from polyurethanes (PUs) synthesized from polyols (derived from castor oil) and isophorone diisocyanate were evaluated. In vitro degradability was evaluated by phosphate buffered saline (PBS) and antibacterial degradation with Escherichia coli and Pseudomonas aeruginosa. The biocompatibility was analyzed by: i) the antimicrobial activity against $E$. coli, S. aureus and P. aeruginosa, and ii) in vitro cytotoxicity assays using mouse embryonic fibroblast cell line L-929 in direct contact with the PUs and with NIH/3T3 cells in indirect contact with the PUs degradation products. PUs with polyol P1 (2,64\% molar relation of pentaerythritol and castor oil) was the material with better biodegradation properties: $1.125 \pm 0.110 \%$ in $72 \mathrm{~h}$ by PBS at $100{ }^{\circ} \mathrm{C}$. In general, all materials were degraded up to $1.000 \pm 0.223 \%$ and $2.251 \pm 0.010 \%$ in $72 \mathrm{~h}$ by E. coli and P. aeruginosa, respectively. On the other hand, it was determined a close relationship between functionality of polyol and bacterial inhibition. The antibacterial effect of the PUs decreased by $67 \%$ for E. coli, $55 \%$ for S. aureus and $56 \%$ for P. aeruginosa after $24 \mathrm{~h}$. Chemical modification of castor oil did not generate a cytotoxic effect on the tested cell lines. The evaluated materials are suggested as candidates to obtain biomaterials due to their mechanical properties and biocompatibility presented in untransformed cells.
\end{abstract}

Keywords: castor oil; polycaprolactone; cytotoxicity; degradability; biomedical applications.

\section{INTRODUCCIÓN}

Los poliuretanos (PUs) representan una popular e importante parte de productos industriales que se caracterizan por tener buenas propiedades de flexibilidad, elevada resistencia al impacto y durabilidad, características que lo convierten en polímeros con múltiples aplicaciones. ${ }^{1}$ Su carácter de copolímero en bloque los dota de una amplia versatilidad en términos de adaptación de sus propiedades físicas y compatibilidad. ${ }^{2-7}$ Es así como los PUs son interesantes para usos internos (in vivo), especialmente en aplicaciones a corto plazo, como catéteres o implantes. De igual forma, son interesantes para aplicaciones de uso externo (in vitro), como por ejemplo los sistemas de liberación controlada de medicamentos. ${ }^{8}$

De esta forma los PUs son polímeros sintéticos biocompatibles que se emplean en dispositivos médicos y en aplicaciones de ingeniería de tejidos. Los PUs empleados como materiales biomédicos deben cumplir con las propiedades mecánicas para la aplicación destino, deben ser no tóxicos, ser biodegradables de acuerdo con la función a cumplir y deben ser biocompatibles. ${ }^{9,10}$ Se han utilizado estrategias para mejorar falencias de estos materiales como las propiedades de fatiga, control de la degradación, incremento de proliferación celular, entre otros. Algunas de estas estrategias consisten en modificar la superficie de los PUs por medio de procesos físicos o químicos. ${ }^{11}$

La evaluación citotóxica es uno de los estudios in vitro usados comúnmente para determinar la biocompatibilidad de un material y presenta una correspondencia de un $97 \%$ con los ensayos de implantación. Es un estudio simple, rápido y económico que proporciona una valiosa información de los materiales que deben ser descartados o aquellos que deben ser sometidos a más estudios. Se han empleado muchos métodos para determinar la citotoxicidad de los biomateriales y equipos médicos implantables, estos consisten

*e-mail: manuelvv@unisabana.edu.co en observar la inhibición del crecimiento celular o registrar el daño o muerte celular. Las pruebas de citotoxicidad empleadas con más frecuencia incluyen la evaluación de la citotoxicidad por contacto directo e indirecto. ${ }^{12}$

Los polímeros biodegradables han ganado mucha atención hoy en día en el campo de la medicina con el objetivo de buscar nuevos materiales para tratamientos de problemas de salud debido a sus atractivas propiedades físicas y su buena biocompatibilidad. ${ }^{13,14} \mathrm{La}$ biodegradabilidad de los PUs se logra generalmente por la incorporación de fracciones fáciles de transformar e hidrolizables dentro de las cadenas principales del polímero. ${ }^{13}$ Adicional a esto, se ha encontrado una correlación entre flexibilidad y la biodegradabilidad, lo que indica que cuanto más flexible sea el PU, éste será más susceptible a biodegradación. ${ }^{15}$ Dentro de este marco, se han empleado los aceites esenciales de diferentes semillas oleaginosas (soya, coco, girasol, higuerilla, palma, entre otros) para sintetizar PUs biodegradables, debido a que son económicos, no tóxicos, abundantes y contienen grupos hidroxilos secundarios y triglicéridos de ácidos grasos. ${ }^{16-20}$

Dentro de los aceites mencionados el aceite de higuerilla se obtiene de una fuente renovable y la producción se caracteriza por tener bajos precios lo que reduce el costo de la síntesis de PUs y adicional a esto se obtiene un beneficio para el medio ambiente. De otro lado, el aceite de ricino tiene un alto índice hidroxilo que puede reaccionar a temperatura ambiente con un consumo relativamente bajo de energía. ${ }^{21-23}$

Modificaciones químicas de la estructura permiten variar propiedades como el porcentaje de degradación, la hidrofobicidad, entre otros. ${ }^{24}$ Existen investigaciones enfocadas en evaluar polioles derivados del aceite de higuerilla debido a la composición, estructura química y funcionalidad del aceite. En búsqueda de aumentar la funcionalidad de los polioles del aceite de higuerilla se han realizado estudios para modificar el aceite de higuerilla por transesterificación con lo que se han logrado mejoras en las propiedades mecánicas. ${ }^{21,25}$ 
A pesar de los importantes avances en estos temas de investigación, aún son muchos los retos que se deben superar en el diseño de materiales en el campo de la biomedicina. Uno de los grandes retos es hacer uso de precursores de polímeros que sean obtenidos a partir de fuentes renovables como es el caso de los aceites vegetales, específicamente el aceite de higuerilla, el cual por el alto contenido del triglicérido de ácido ricinoléico permite obtener polioles con gran número de grupos hidroxilos reactivos mediante modificación química, lo que conlleva a un aumento en sus propiedades mecánicas. Es importante mencionar que se cuenta con pocos estudios del potencial de uso como biomaterial de PUs obtenidos a partir de aceite de higuerilla y polioles derivados del aceite modificado por medio de modificación química.

Es así como el objetivo de este estudio fue evaluar las propiedades biológicas que poseen PUs sintetizados en un estudio previo de nuestro grupo de investigación. Los PUs estaban sintetizados a partir de polioles derivados del aceite de higuerilla (con y sin modificación química) y diisocianato de isoforona (IPDI). Las propiedades biológicas consistían en determinar el porcentaje de degradación acelerada en PBS y la degradación microbiana de los PUs por bacterias como Escherichia coli y Pseudomonas aeruginosa; evaluar la actividad antibacteriana de los PUs sobre bacterias que comúnmente habitan en centros médicos como Escherichia coli, Staphylococcus aureus y Pseudomonas aeruginosa; y evaluar la citotoxicidad in vitro de fibroblastos embrionarios de ratón L-929 (ATCC CCL-1). También se investigó la citocompatibilidad de los extractos de degradación de estos PUs sobre fibroblastos de ratón NIH/3T3 (ATCC CRL-1658).

\section{EXPERIMENTAL}

\section{Reactivos}

Aceite de higuerilla (AH) marca Ciacomeq S.A.S (Colombia), Policaprolactona diol (PCL) (peso molecular promedio de 2000 $\mathrm{g} \mathrm{mol}^{-1}$ ) marca Sigma-Aldrich (USA), Diisocianato de isoforona (IPDI) marca Merck (USA). Buffer fosfato salino (PBS: $0,01 \mathrm{~mol} \mathrm{~L}^{-1}$ $\mathrm{KH}_{2} \mathrm{PO}_{4}-\mathrm{NaHPO}_{4}$ con $0,8 \% \mathrm{NaCl}, \mathrm{pH}$ 7,4). MTT (3-[4,5-dimethylthiazol-2-yl]-2,5-diphenyl-2H-tetrazolium bromide), tripsina $2.5 \%$ (10X), Penicilin-Streptomycin (contiene 10.000 Und de penicilina y $10.000 \mu \mathrm{g}$ de estreptomicina por mililitro) para uso en cultivo celular, D-MEM (Dulbecco's Modified Eagle Medium) (1X), RPMI 1640 (Roswell Park Memorial Institute) fueron marca Gibco/Invitrogen, Paisley, UK. Suero fetal bovino (FBS) marca Eurobio (Les Ulis, France). Caldo tripticasa soya (TSB) y Agar tripticasa soya (TSA) marca Scharlau Co (España), Fibroblastos embrionarios de ratón NIH/3T3 (ATCC ${ }^{\circledR}$ CRL-1658) y L-929 (ATCC ${ }^{\circledR}$ CCL-1). Escherichia coli (ATCC ${ }^{\circledR}$ 2469), Staphylococcus aureus $\left(\mathrm{ATCC}^{\circledR}\right.$ 6538) y Pseudomonas aeruginosa (ATCC ${ }^{\circledR} 27853$ ) fueron adquiridos de la biblioteca de cepas de la Universidad de La Sabana.

\section{Materiales poliméricos}

Los materiales poliméricos empleados en este artículo se sintetizaron por nuestro grupo de investigación en un estudio previo reportado por Valero y Ortegón. ${ }^{25}$ Se utilizaron 3 polioles diferentes (AH, P0 y P1) donde P0 y P1 fueron modificados químicamente por medio de transesterificación con pentaeritritol (1,32\% y $2,64 \%$ mol de pentaeritritol/mol de aceite de higuerilla, respectivamente). La reacción de transesterificación se realizó en un balón reactor de 3 bocas con agitación y control de temperatura. Una etapa inicial consistió en la deshidratación del aceite de higuerilla a una temperatura de $120^{\circ} \mathrm{C}$ por $10 \mathrm{~min}$. Luego se adicionó pentaeritritol y óxido de plomo al $0,05 \%$ como catalizador a una temperatura de $210{ }^{\circ} \mathrm{C}$ durante $2 \mathrm{~h}$. El índice hidroxilo de los polioles se determinó por medio de la norma ASTM D1957-86. Los PUs (descritos en la Tabla 1) se sintetizaron por medio del método del pre-polímero con IPDI manteniendo una relación (1:1) constante NCO/OH. El IPDI se adicionó al poliol a una temperatura de $60{ }^{\circ} \mathrm{C}$ y $300 \mathrm{rpm}$, luego se adicionó PCL por $5 \mathrm{~min}$. El pre-polímero obtenido se sometió a vacío y fue vertido en un molde de acero. El proceso de curado fue a $110^{\circ} \mathrm{C}$ durante $12 \mathrm{~h}$.

Tabla 1. Identificación de poliuretanos

\begin{tabular}{ccc}
\hline Nombre Poliuretano & Poliol & Diisocianato \\
\hline \multirow{2}{*}{ AH } & $\begin{array}{c}\text { Aceite de higuerilla } \\
\text { (índice hidroxilo } \\
163 \mathrm{mg} \mathrm{KOH} \mathrm{g}^{-1} \text { ) }\end{array}$ & \\
& $\begin{array}{c}\text { Aceite de higuerilla } \\
\text { (índice hidroxilo } \\
\text { P0 }\end{array}$ & $\begin{array}{c}\text { Diisocianato de } \\
\text { isoforona (IPDI) }\end{array}$ \\
& $\begin{array}{c}\text { Aceite de higuerilla } \\
\text { (índice hidroxilo }\end{array}$ & \\
\hline \multirow{3}{*}{ P1 } & $236 \mathrm{mg} \mathrm{KOH} \mathrm{g}^{-1}$ ) & \\
&
\end{tabular}

En un estudio previo realizado en nuestro grupo de investigación por Ortegón ${ }^{26}$ sobre la estabilidad térmica de los PUs sintetizados se determinó que todas las matrices son estables térmicamente por debajo de $200{ }^{\circ} \mathrm{C}$ y se descomponen alrededor de $500{ }^{\circ} \mathrm{C}$.

\section{Estudios de degradación in vitro}

\section{Degradación acelerada en buffer fosfato salino}

El efecto de la temperatura sobre la degradación de los materiales poliméricos es importante para desarrollar métodos de degradación acelerada que ahorran tiempo y acortan ciclos de desarrollo de dispositivos médicos..$^{27,28} \mathrm{La}$ degradación acelerada se realizó a $100{ }^{\circ} \mathrm{C}$ durante un periodo de 24, 48 y $72 \mathrm{~h}$ en buffer fosfato salino siguiendo la metodología descrita por Perales-Alcacio. ${ }^{11}$ Para estos ensayos se utilizaron polímeros estériles de $9 \mathrm{~mm}$ de diámetro y se colocaron en $5 \mathrm{~mL}$ de buffer. Las muestras de los polímeros se retiraron del buffer, se secaron a $40{ }^{\circ} \mathrm{C}$ por $24 \mathrm{~h}$ y se pesaron. Tres medidas independientes fueron realizadas para cada muestra. El porcentaje de pérdida de peso se determinó con la ecuación 1:

$\%$ pérdida de peso $=\frac{\left(m a s a_{\text {inicial }}-m a s a_{\text {final }}\right)}{m a s a_{\text {final }}} \times 100$

\section{Degradación microbiológica}

La degradación microbiológica fue cuantificada por el peso de los polímeros antes y después de incubación en suspensión bacteriana según metodologías modificadas de Uribe et al. y Ates et al. ${ }^{29,30}$ Para estos ensayos se utilizaron polímeros estériles de 9 $\mathrm{mm}$ de diámetro y se colocaron en $5 \mathrm{~mL}$ de caldo TSB estéril con un inóculo inicial de $10 \mu \mathrm{L}$ de $E$. coli $\left(\mathrm{ATCC}^{\circledR} 25922\right)$ y $P$. aeruginosa $\left(\right.$ ATCC $\left.^{\circledR} 27853\right)(4,2 \mathrm{E}+06$ y 4,8E+06 unidades formadoras de colonias por mililitro, respectivamente) y se incubaron a $37{ }^{\circ} \mathrm{C}$ por $72 \mathrm{~h}$. Las muestras de los polímeros se retiraron de la suspensión bacteriana, se lavaron con etanol al $70 \%$, se secaron a $40{ }^{\circ} \mathrm{C}$ por $24 \mathrm{~h}$ y se pesaron. Tres medidas independientes fueron realizadas para cada muestra. El porcentaje de pérdida de peso se determinó con la ecuación 2:

$\%$ pérdida de peso $=\frac{\left(\text { masa }_{\text {inicial }}-\text { masa }_{\text {final }}\right)}{\text { masa }_{\text {final }}} \times 100$ 


\section{Ensayos antibacterianos de PUs}

La actividad antibacteriana de los PUs se evaluó con base en el método definido por $\mathrm{Kara}^{31}$ contra E. coli $\left(\mathrm{ATCC}^{\circledR} 2469\right)$, S. aureus (ATCC ${ }^{\circledR} 6538$ ) y P. aeruginosa $\left(\right.$ ATCC $^{\circledR} 27853$ ). Las suspensiones bacterianas se obtuvieron por crecimiento en TSB a $37^{\circ} \mathrm{C}$ por $16 \mathrm{~h}$. Alícuotas de la suspensión bacteriana se inocularon en TSB nuevo a $37{ }^{\circ} \mathrm{C}$ por $6 \mathrm{~h}$. Se centrifugó la suspensión bacteriana a $3000 \mathrm{rpm}$ por $10 \mathrm{~min}$. Se realizó lavado de las células 2 veces con PBS luego de remover los sobrenadantes. Las bacterias se disolvieron en PBS a 4,2E+06, 4,0E+06 y 4,8E+06 UFC $\mathrm{mL}^{-1}$, respectivamente.

Para la evaluación de la actividad antibacteriana, los polímeros se colocaron en microplatos de 96 pozos con $100 \mu \mathrm{L}$ de suspensión bacteriana y se incubaron a $37^{\circ} \mathrm{C}$ por $24 \mathrm{~h}$. El contenido de cada pozo fue transferido a tubos de micro-centrífuga que contenían 900 $\mu \mathrm{L}$ de PBS estéril. Por medio del conteo de colonias se determinó el número de células viables en la suspensión utilizando diluciones seriadas sembradas en TSA a $37^{\circ} \mathrm{C}$ por $18 \mathrm{~h}$. Suspensión bacteriana sin polímero fue utilizada como control.

\section{Citotoxicidad in vitro del poliuretano}

\section{Cultivo celular}

Células de fibroblastos de ratón NIH/3T3 y L-929 fueron cultivadas en D-MEM y RPMI 1640 respectivamente, suplementados con $10 \%$ FBS y $1 \%$ penicilina/estreptomicina a $37{ }^{\circ} \mathrm{C}$ y $5 \%$ de $\mathrm{CO}_{2}$ hasta una confluencia del $100 \% .{ }^{32}$ Las células fueron tripsinizadas con tripsina EDTA por 3 min a $37^{\circ} \mathrm{C}$, colectadas y centrifugadas a $2000 \mathrm{rpm}$ por $15 \mathrm{~min}^{33}$

\section{Citotoxicidad in vitro por contacto directo de los PUs}

Se evaluó la citotoxicidad in vitro de las muestras de PUs por medio del método MTT definido en la ISO/CD 10993-5. ${ }^{34}$ Muestras cilíndricas de PUs de $3 \mathrm{~mm}$ de diámetro y $2 \mathrm{~mm}$ de espesor se esterilizaron con UV durante 15 min por cada lado. ${ }^{35}$ Se realizó un pre-cultivo de células de fibroblastos de ratón L-929 en placas de 96 pozos (4,0E+04 células/ pozo) con RPMI 1640 suplementado con FBS a $37{ }^{\circ} \mathrm{C}, 5 \% \mathrm{CO}_{2}$ por $24 \mathrm{~h}$. Luego se adicionaron láminas de poliuretano y $100 \mu \mathrm{l}$ de RPMI sin suplementar por $24 \mathrm{~h}$ bajo las mismas condiciones de ensayo. Se eliminó el sobrenadante y se agregaron $100 \mu$ l de solución de MTT 12 $\mathrm{mM}$ en PBS estéril a cada pozo y se incubó a $37^{\circ} \mathrm{C}$ por $4 \mathrm{~h}$. La solución fue removida y se agregó dimetilsulfoxido (DMSO) a cada pozo y se incubó a $37^{\circ} \mathrm{C}$ por $15 \mathrm{~min}$. Se realizó la lectura de densidad óptica en un iMark ${ }^{\mathrm{TM}}$ Microplate Reader a una longitud de onda de $595 \mathrm{~nm}$. Se utilizaron células sembradas sin polímero y DMSO como controles. Adicionalmente se utilizó un polímero comercial (polipropileno) para evaluar la viabilidad. Todos los ensayos fueron realizados por triplicado. El porcentaje de viabilidad se calculó con la ecuación $3: 36$

$\%$ de viabilidad $=\frac{\left(A b s_{\text {muestra }}\right)}{A b s_{\text {control }}} \times 100$

Donde $\mathrm{Abs}_{\text {muestra }}$ es la absorbancia de las células luego de ser tratadas con la muestra y $\mathrm{Abs}_{\text {control }}$ es la absorbancia de las células sin muestra.

\section{Citotoxicidad de productos de degradación}

Muestras de polímeros de $4 \mathrm{~mm}$ de diámetro para la prueba de citotoxicidad fueron esterilizados con luz UV. ${ }^{35}$ Para obtener el extracto se utilizaron tres muestras de cada composición de los polímeros en tubos de micro-centrífuga con $100 \mu \mathrm{L}$ de D-MEM a $37^{\circ} \mathrm{C}, 200 \mathrm{rpm}$ por 30 días. Con $100 \mu \mathrm{L}$ de sobrenadante se determinó la citotoxicidad de los productos de degradación por medio del ensayo MTT según metodología del ítem anterior. La citotoxicidad de los productos de degradación fue evaluada con células de fibroblastos de ratón NIH/3T3 sembradas en placas de $96 \operatorname{pozos}^{37}$ (4,0E+04 células/pozo) con D-EMEM suplementado con FBS a $37^{\circ} \mathrm{C}, 5 \% \mathrm{CO}_{2}$ por $24 \mathrm{~h}$.

\section{Análisis estadístico}

Los resultados fueron analizados por medio de un análisis de varianza (ANOVA) y las diferencias significativas fueron determinadas para $\mathrm{p}<0.05$. Para la comparación entre muestras se utilizó la prueba t-Student con el Software SPSS Statistics 23. Todos los experimentos fueron realizados usando tres réplicas independientes. Todos los resultados se reportan como media \pm desviación estándar.

\section{RESULTADOS Y DISCUSIÓN}

\section{Estudios de degradación in vitro}

Degradación acelerada en buffer fosfato salino

La degradación acelerada con PBS se evaluó durante tres periodos de tiempo (24, 48 y 72 h) y los resultados se presentan en la Figura 1.

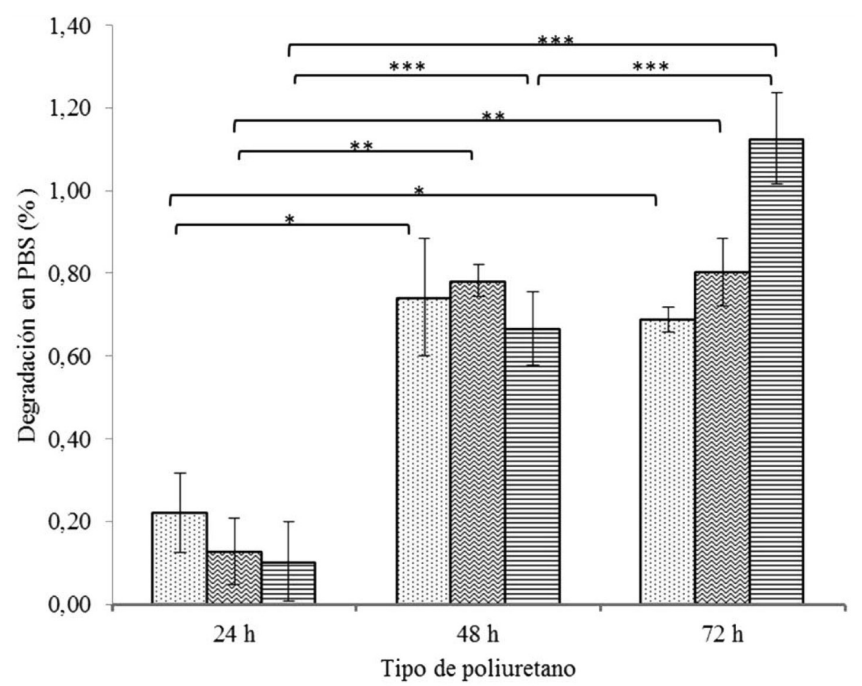

Figura 1. Porcentaje de degradación acelerada en PBS de PUs a 24 h, 48 hy

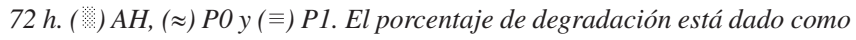
medias \pm S.D. $(n=3)$. *, **y $* * *$ indican diferencias estadísticas significativas para cada poliol ( (: $) A H,(\approx) P 0 y$ (三) P1), respectivamente

Según los resultados presentados en la Figura 1 se puede decir que a las $24 \mathrm{~h}$ se observan diferencias estadísticas $(\mathrm{p}<0.05)$ entre el poliol AH con los polioles P0 y P1 siendo el porcentaje de degradación de $\mathrm{AH}$ inferior comparado con P0 y P1 bajo las condiciones del ensayo. P0 y P1 no presentan diferencias significativas. De igual forma a las $48 \mathrm{~h}$ se observan diferencias estadísticas $(\mathrm{p}<0.05)$ entre $\mathrm{AH}$ con $\mathrm{P} 0$ y $\mathrm{P} 1$ reiterando el mismo comportamiento de las $24 \mathrm{~h}$ donde el porcentaje de degradación de $\mathrm{AH}$ es inferior al obtenido cuando se incrementan los grupos hidroxilo. Igual que en el caso anterior P0 y P1 no presentan diferencias significativas. En cuanto a los resultados de degradación acelerada a las $72 \mathrm{~h}$ se observan diferencias estadísticas $(\mathrm{p}<0.05)$ entre $\mathrm{AH}$ con $\mathrm{P} 0$ y P1 y al comparar $\mathrm{P} 0$ con $\mathrm{P} 1$ se observan diferencias significativas indicando que el poliol que contiene un incremento en sus grupos hidroxilo presenta valores de degradación elevados, en este caso se obtiene un 1,12\% de degradación. En un estudio previo desarrollado en nuestro grupo de investigación por Ortegón ${ }^{26}$ se determinó el ángulo de contacto de estos polímeros y se encontró que las superficies tienden a ser 
hidrofílicas lo cual está relacionado con la degradación de los mismos.

Con los resultados presentados en la Figura 1 se puede inferir que al realizar estudios de degradación en PBS acelerado con temperatura se obtiene degradación de los PUs en periodos de 72 h. La degradación de PUs en PBS tiende a presentar porcentajes bajos de degradación en el corto tiempo como se ha reflejado en estudios previos de nuestro grupo de investigación. Esto coincide con el estudio realizado por Ruan et al. quienes evaluaron la degradación por medio de la pérdida de masa de los PUs en PBS a $37^{\circ} \mathrm{C}$ durante doce semanas y afirman que durante las primeras cuatro semanas la pérdida de peso es baja, diferente a lo que sucede luego de la quinta semana de evaluación. ${ }^{38}$ De igual forma Ates et al. evaluaron la degradación in vitro de PUs en PBS a $37^{\circ} \mathrm{C}$ durante periodos de $1,2,3,4,6$ y 8 semanas. Los autores afirman que si un PU contiene una mayor proporción de grupos polares en su estructura se facilita la degradación lo que coincide con los polioles modificados empleados para nuestro estudio. ${ }^{30}$

\section{Degradación microbiológica}

La degradación microbiológica de los PUs con E. coli y $P$. aeruginosa a $37{ }^{\circ} \mathrm{C}$ fue evaluada durante $72 \mathrm{~h}$. La degradación se determinó por medio de la pérdida de masa de los PUs. Los resultados del porcentaje de degradación microbiana se presentan en la Figura 2.

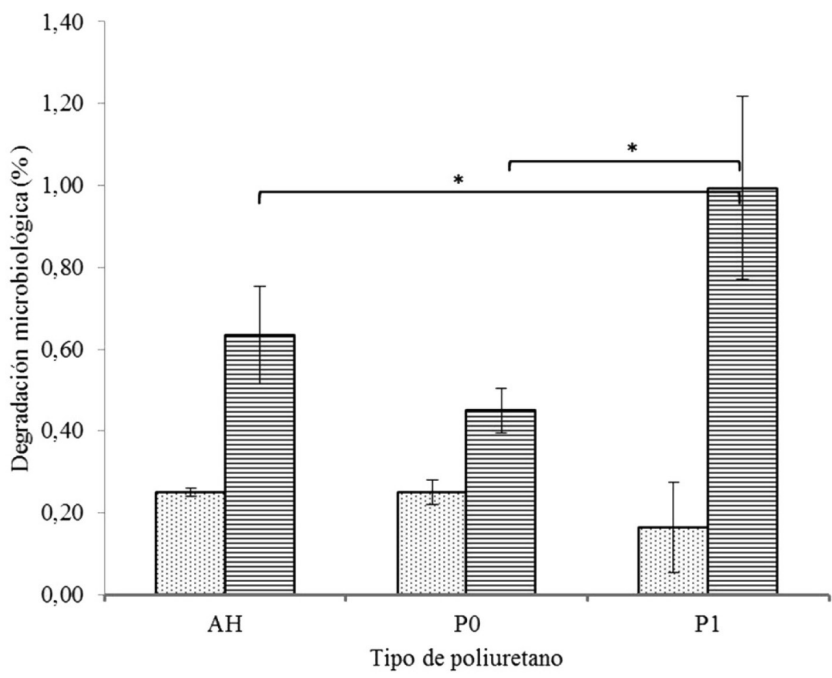

Figura 2. Porcentaje de degradación microbiológica de PUs a 72 h. (:) E. coli, (三) P. aeruginosa. El porcentaje de degradación está dado como medias \pm S.D. ( $n=3)$. * indica diferencias estadísticas significativas en cada poliol con (三) P. aeruginosa

Como se observa en la Figura 2 PUs con diferntes polioles derivados del aceite de higuerilla presentaron degradación a las $72 \mathrm{~h}$ por bacterias Gram negativas de E. coli y P. aeruginosa. Por medio de análisis estadístico se observó que para $E$. coli no se presentan diferencias significarivas $(\mathrm{p}<0.05)$ según el tipo de poliol. Para $P$. aeruginosa se observaron diferencias estadìsticamente significativas de P1 comparado con $\mathrm{AH}$ y P0, es así como se determinó que P1 es el poliol que presenta mayor efecto estadístico sobre el porcentaje de degradación para este tipo de bacteria. Según Larraza ${ }^{39}$ valores de degradación elevados se obtienen por bacterias Gram negativas. Esto probablemente sea debido a la adherencia de los microorganismos en la superficie de los polímeros gracias a la estructura característica de los PUs, según lo describe Gogoi ${ }^{40}$ en un estudio donde evaluó la degradación de PUs por $P$. aeruginosa.

Estos comportamientos pueden ser atribuidos a un incremento de los grupos hidroxilo en el poliol P1 comparado con los otros polioles evaluados lo que genera un incremento en el entrecruzamiento físico del polímero y por lo tanto se tiene un aumento en los grupos uretano. Los enlaces uretanos son similares a las amidas y pueden ser hidrolizables por enzimas presentes en las bacterias empleadas para el ensayo. ${ }^{41,42}$ Esto coincide con lo expuesto por Gogoi ${ }^{40}$ donde se describe que la presencia de enlaces amida y urea presentes en la estructura ramificada del polímero facilita la degradación. Según Cherng la degradación de los PUs es debida a la ruptura de enlaces hidrolíticamente débiles característicos de los segmentos suaves y por lo tanto concluyen que la velocidad de degradación in vitro depende principalmente del tipo de poliol utilizado en la síntesis por el tipo de enlaces éster que se encuentran en la estructura. ${ }^{41}$

\section{Ensayos antibacterianos del poliuretano}

Un material con actividad bacteriana puede disminuir la colonización bacteriana y prevenir infecciones por lo que la protección antibacterial es un factor fundamental cuando se diseñan biomateriales. Por tal motivo se determinó la actividad antibacteriana de los PUs contra bacterias Gram negativas (E. coli y P. aeruginosa) y una bacteria Gram positiva (S. aureus) por medio del conteo de las unidades formadoras de colonia luego de 24 h de exposición de los polímeros con cada bacteria. En las figuras 3, 4 y 5 se presentan los resultados de la actividad antibacteriana que presentan los PUs contra E. coli, S. aureus y P. aeruginosa, respectivamente.

Al realizar un análisis estadístico para los resultados de la Figura 3 se observa que para E. coli existen diferencias estadísticamentes significativas $(\mathrm{p}<0.05)$ entre los polioles $\mathrm{AH}$ con $\mathrm{P} 0$ y $\mathrm{P} 1$ y adicional se observa que el control es diferente significaticamente con el poliol P1 indicando que el poliol P1 tiene el porcentaje de inhibición más alto para E. coli bajo las condiciones del ensayo.

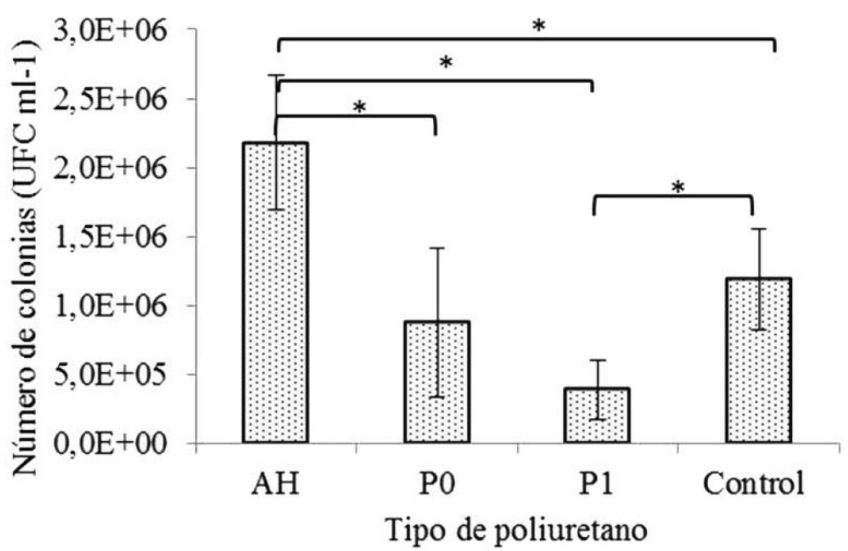

Figura 3. Ensayo antibacteriano de PUs con E. coli. Las unidades formadoras de colonia por mililitro de muestra original (UFC $\mathrm{mL}^{-1}$ ) están dadas como medias \pm S.D. $(n=3)$. * indica diferencias estadísticas significativas para cada poliol

Para los resultados relacionados con $S$. aureus según se observa en la Figura 4 no existen diferencias estadísticamente significativas entre los tipos de polioles, pero sí existen diferencias estadísticas entre los 3 tipos de polioles con el control por lo que se puede inferir que PUs sintetizados con los polioles AH, P0 y P1 derivados del aceite de higuerilla inhiben a $S$. aureus.

Para el último ensayo de inhibición bacteriana relacionada con $P$. aeruginosa (Figura 5) se observó que no existen diferencias entre los tipos de polioles, pero si existen diferencias estadísticas entre los 3 tipos de polioles con el control. De acuerdo con los resultados observados se puede concluir que los poliuretanos evaluados en este estudio presentan inhibición bacteriana contra $P$. aeruginosa. 


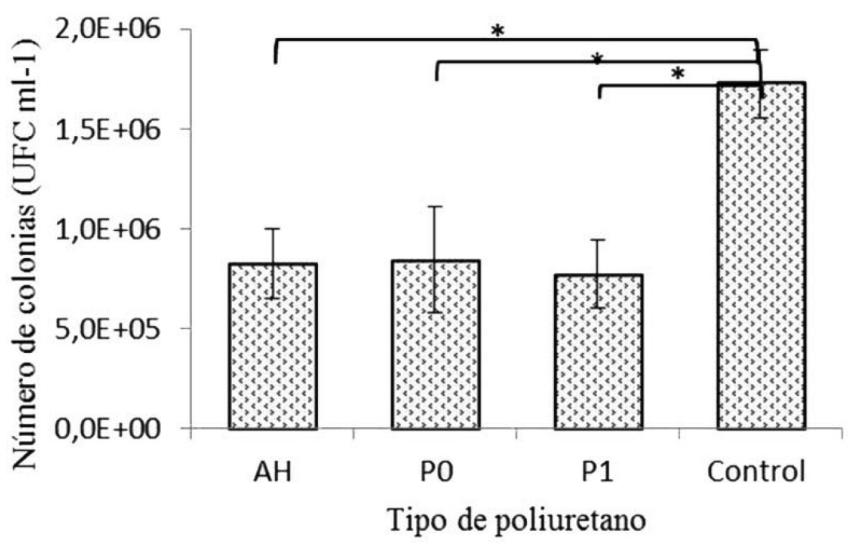

Figura 4. Ensayo antibacteriano de PUs con S. aureus. Las unidades formadoras de colonia por mililitro de muestra original (UFC $\mathrm{mL}^{-1}$ ) están dadas como medias \pm S.D. $(n=3)$. * indica diferencias estadísticas significativas para cada poliol

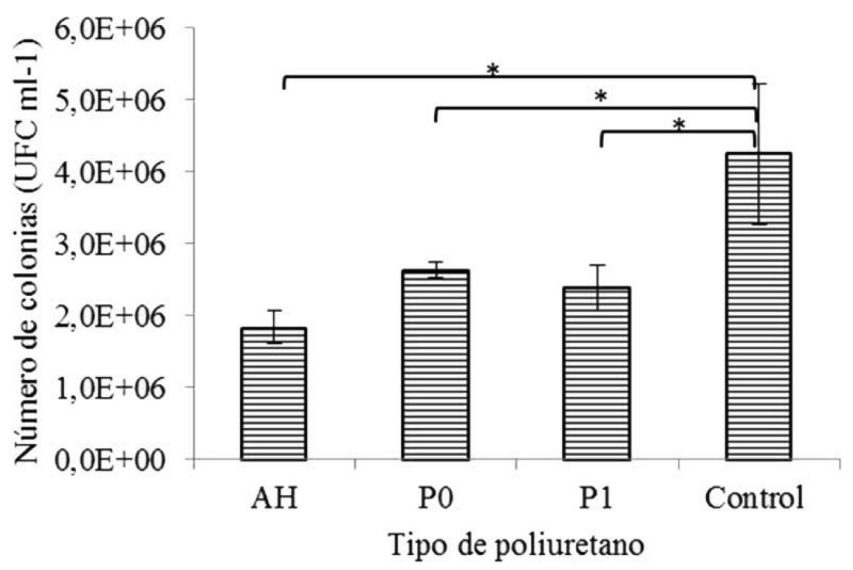

Figura 5. Ensayo antibacteriano de PUs con P. aeruginosa. Las unidades formadoras de colonia por mililitro de muestra original $\left(U F C{ }^{-1}\right)$ están dadas como medias \pm S.D. $(n=3)$. * indica diferencias estadísticas significativas para cada poliol

Con los resultados anteriores se observó que los materiales poliméricos evaluados presentan actividad antimicrobiana y adicional a esto el aumento del índice hidroxilo en los polioles (determinado en un estudio previo por el grupo de investigación $)^{26}$ mejora los resultados de inhibición bactariana. Esto coincide con un estudio realizado por Kara et al. donde evaluaron $S$. aureus y $S$. epidermidis (Gram positivas) y E. coli y P. aeruginosa (Gram negativas) sobre PUs sintetizados con diisocianato de hexametileno y con adición de quitosano y heparina para generar incremento en la actividad antibacteriana. Ellos reportaron una eficiente actividad antibacteriana comparada con el blanco de todos las bacterias evaluadas y atribuyen esto a la presencia de grupos polares que pueden quelar fácilmente o interactuar con algunos cationes que desempeñan un papel clave para el metabolismo de las bacterias, o pueden perturbar el enlace de hidrógeno estable en el entorno de las bacterias, o pueden unirse directamente a los organismos y provocar su muerte. ${ }^{43}$ blood vessels, vascular grafts and catheters

En un estudio previo Tijing et al. evaluaron la actividad antimicrobiana de PUs con nanopartículas de plata y óxido de polietileno contra la bacteria Gram negativa de E. coli por medio de inhibición en placa y encontraron zonas de inhibición atribuidas a la presencia de las nanopartículas de plata que tienen efecto antibacterial. ${ }^{44}$ De esta forma se puede decir que son diversos los factores de los materiales que influyen en el crecimiento microbiano como la hidrofobicidad de la superficie, la rugosidad, la química del material, entre otros. ${ }^{45}$

\section{Citotoxicidad in vitro del poliuretano}

Se evaluó la compatibilidad de los PUs por medio de la determinación de la viabilidad celular de células L-929 en contacto directo con los materiales poliméricos y los resultados se presentan en la Figura 6.

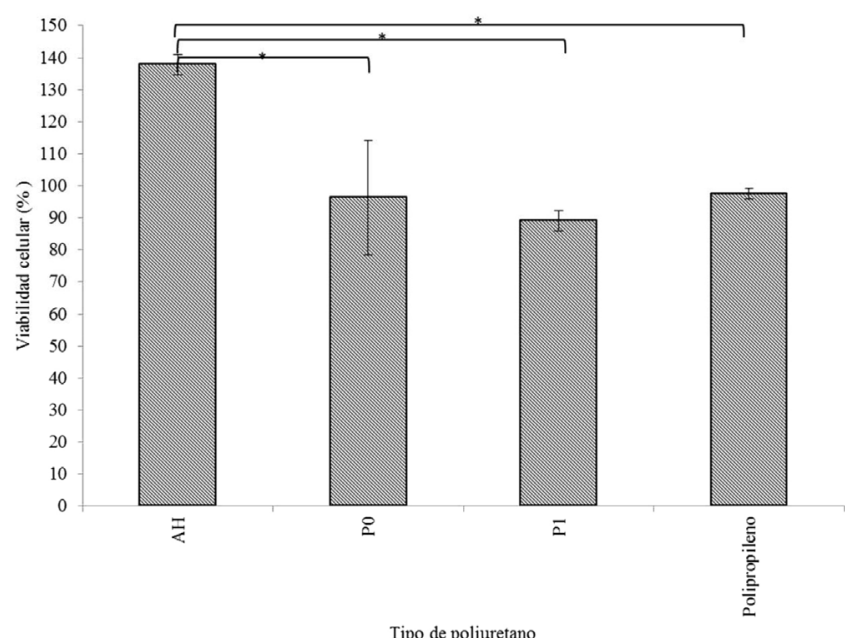

Figura 6. Porcentaje de viabilidad celular de fibroblastos L-929 a $24 \mathrm{~h}$. El porcentaje de viabilidad está dado como medias \pm S.D. $(n=3)$.* indica diferencias estadísticas significativas para cada poliol

Con respecto a los resultados del porcentaje de viabilidad de las células L-929 luego de estar en contacto con los PUs se observó que existen diferencias estadísticamente significativas $(\mathrm{p}<0.05)$ entre los polioles empleados. Es así como se observó que el poliol denominado $\mathrm{AH}$ es diferente estadísticamente con los polioles P0 y P1 presentando los valores más altos de viabilidad celular bajo las condiciones del ensayo.

Según los resultados reportados en la Figura 6 se puede inferir que los PUs sintetizados con polioles derivados del aceite de higuerilla presentaron una toxicidad baja o nula para las células de fibroblastos L-929 in vitro. Los porcentajes de viabilidad celular son superiores al $70 \%$ por lo tanto los resultados pueden ser comparables con el control positivo utilizado que correspondía a un polipropileno comercial utilizado como biomaterial.

Bakhshi et al. evaluaron PUs sintetizados con adición de sales de amonio cuaternario en la epoxidación de aceite de soya y encontraron que los PUs presentan una viabilidad celular entre el 78-108\% de fibroblastos de ratón L-929 demostrando que no existía toxicidad de los polímeros sintetizados coincidiendo esto con los resultados de

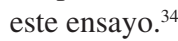

Resultados similares fueron encontrados por Calvo-Correas et al. quienes en un estudio preliminar de citotoxicidad in vitro con células murinas L-929 determinaron que PUs sintetizados a partir de aceite de higuerilla y diisocianato de lisina presentaban una viabilidad celular superior al $100 \%$ en las primeras $24 \mathrm{~h}$ de ensayo, siguiendo el protocolo estándar de la ISO 10993-12, lo cual indicaba que los PUs sintetizados resultaban no tóxicos, mostrando un potencial uso en aplicaciones biomédicas. ${ }^{36}$ De igual forma estos resultados coinciden con los reportados por Reddy et al. quienes sintetizaron un poliuretano a partir de diisocianato de lisina, PCL y 1,4-butanodiamida, y encontraron que los polímeros no presentaban toxicidad cuando estaban en contacto con fibroblastos de ratón $\mathrm{NIH} 3 \mathrm{~T} 3 .{ }^{46}$ 


\section{Citotoxicidad de productos de degradación}

Se realizó la evaluación de los extractos o productos de degradación de los PUs para determinar si eran tóxicos para una línea celular. Para este ensayo se utilizaron fibroblastos de ratón NIH/3T3 las cuales fueron cultivadas con extractos de polímeros luego de 30 días de incubación y por medio del ensayo MTT se determinó el porcentaje de viabilidad celular. Los resultados de este ensayo se presentan en la Figura 7.

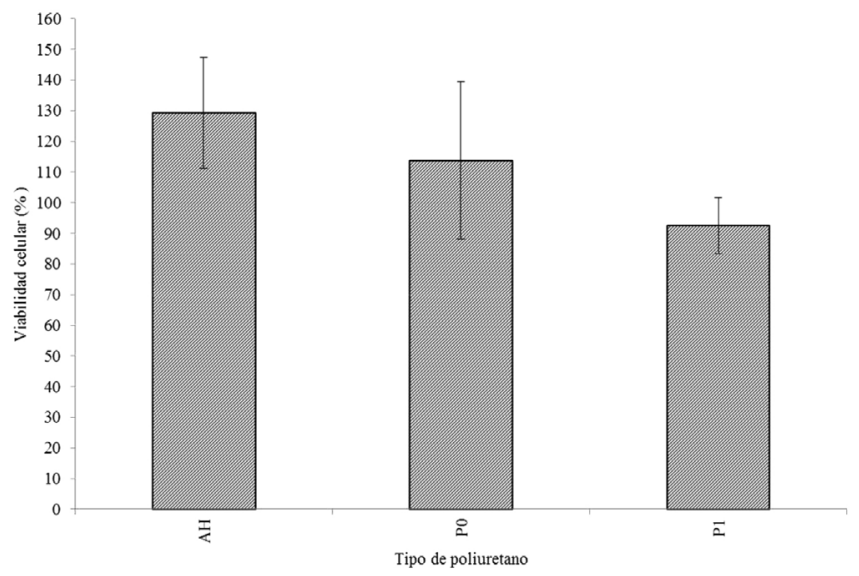

Figura 7. Porcentaje de viabilidad celular de fibroblastos NIH/3T3 a $24 \mathrm{~h} . \mathrm{El}$ porcentaje de viabilidad está dado como medias \pm S.D. $(n=3)$

De acuerdo con los resultados presentados en la Figura 7 se observa que las células permanecieron viables luego de evaluar los extractos de los PUs y, adicional al realizar el análisis estadístico no se observaron diferencias significativas $(\mathrm{p}<0.05)$ entre los tipos de polioles empleados en la síntesis indicando que todos los PUs evaluados presentan la misma tendencia y por lo tanto se puede concluir que los extractos de los materiales poliméricos no presentan efectos nocivos para los fibroblastos de ratón NIH/3T3.

Estos resultados concuerdan con los evaluados por Giannitelli et al. quienes evaluaron extractos de PUs sobre cultivo celulares de fibroblastos $3 \mathrm{~T} 3 \mathrm{y}$ los resultados revelaron una excelente supervivencia (superior al $80 \%$ de viabilidad) de las células confirmando una citotoxicidad insignificante de los materiales poliméricos evaluados. ${ }^{47}$

\section{CONCLUSIONES}

Poliuretanos sintetizados con polioles derivados del aceite de higuerilla y diisocianato de isoforona se utilizaron para evaluar propiedades biológicas como el porcentaje de degradación acelerada en PBS y degradación microbiana por bacterias de E. coli y P. aerugino$s a$; la actividad antibacteriana de los PUs sobre las bacterias E. coli, $S$. aureus y P. aeruginosa; y la citotoxicidad in vitro de fibroblastos L-929 y NIH/3T3. Polímeros basados en poliol con mayor índice hidroxilo (P1) presentaron porcentajes de degradación de 1,12\% a las $72 \mathrm{~h}$ de ensayo y 1,0\% para la degradación microbiana a las $72 \mathrm{~h}$ con $P$. aeruginosa. Todos los materiales poliméricos evaluados presentaron inhibición bacteriana contra E. coli, S. aureus y $P$. aeruginosa comparados con los controles. Con respecto a la evaluación citotóxica de los PUs sobre fibroblastos de ratón L-929 en contacto directo se observó que los PUs presentan porcentajes de viabilidad celular superior al $70 \%$ indicando que son aptos para ser empleados como biomateriales. Adicional a esto, se observó que los extractos de los polímeros no parecen ser tóxicos para células de fibroblastos NIH/3T3. Por las propiedades biocompatibles de los PUs evaluadas en este estudio se pude inferir que indican su idoneidad en aplicaciones biomédicas para la ingeniería de tejidos blandos o generación de suturas biomédicas de acuerdo a sus propiedades mecánicas donde el incremento de la viabilidad celular sea requerido.

\section{AGRADECIMIENTOS}

A la Universidad de La Sabana por la financiación del proyecto de investigación ING-150-2014 el cual hace parte de esta investigación.

\section{REFERENCIAS}

1. Špírková, M.; Serkis, M.; Poręba, R.; Machová, L.; Hodan, J.; Kredatusová, J.; Kubies, D.; Zhigunov, A.; Polym. Degrad. Stab. 2016, 125, 115.

2. Morral-Ruíz, G.; Melgar-Lesmes, P.; García, M. L.; Solans, C.; García-Celma, M. J.; Int. J. Pharm. 2014, 461, 1. http://dx.doi.org/10.1016/j. ijpharm.2013.11.026

3. Chan-Chan, L. H.; Solis-Correa, R.; Vargas-Coronado, R. F.; Cervantes-Uc, J. M.; Cauich-Rodríguez, J. V.; Quintana, P.; Bartolo-Pérez, P.; Acta Biomater. 2010, 6, 2035.

4. Mahkam, M.; Sharifi-Sanjani, N.; Polym. Degrad. Stab. 2003, 80, 199.

5. Shourgashti, Z.; Khorasani, M. T.; Khosroshahi, S. M. E.; Radiat. Phys. Chem. 2010, 79, 947.

6. Qiu, H.; Li, D.; Chen, X.; Fan, K.; Ou, W.; Chen, K. C.; Xu, K.; J. Biomed. Mater. Res. A 2013, 101, 75.

7. Duli ska-Molak, I.; Lekka, M.; Kurzydłowski, K. J.; Appl. Surf. Sci. 2013, 270, 553 .

8. Rodríguez-Galán, A.; Franco, L.; Puiggal, J. En Handbook of Biodegradable Polymers: Synthesis, Characterization and Applications; Lendlein, A.; Sisson, A., orgs.; First 2011, cap. 6.

9. Kucinska-Lipka, J.; Gubanska, I.; Janik, H.; Sienkiewicz, M.; Mater. Sci. Eng. C. Mater. Biol. Appl. 2015, 46, 166

10. Tsai, M.-C.; Hung, K.-C.; Hung, S.-C.; Hsu, S.; Colloids surfaces. B Biointerfaces 2015, 125, 34

11. Perales-Alcacio, J. L. A.; Santa-Olalla Tapia, J.; Mojica-Cardoso, C.; Vargas-Coronado, R. F.; Chan-Chan, L. H.; Headen, D. M.; García, a J.; Cervantes-Uc, J. M.; Cauich-Rodríguez, J. V.; J. Biomater. Sci. Polym. Ed. 2013, 24, 1601

12. Mondal, S.; Martin, D.; Polym. Degrad. Stab. 2012, 97, 1553.

13. Zhou, L.; Yu, L.; Ding, M.; Li, J.; Tan, H.; Wang, Z.; Fu, Q.; Macromolecules 2011, 44, 857.

14. Zia, K. M.; Barikani, M.; Zuber, M.; Bhatti, I. A.; Bhatti, H. N.; Iran. Polym. J. 2008, 17, 61 .

15. Zia, K. M.; Barikani, M.; Zuber, M.; Bhatti, I. A.; Sheikh, M. A.; Carbohydr. Polym. 2008, 74, 149.

16. Miao, S.; Wang, P.; Su, Z.; Zhang, S.; Acta Biomater. 2014, 10, 1692.

17. Firdaus, F. E.; Mater. Sci. Eng. 2014, 58, 012023.

18. Valério, A.; Araújo, P.; Sayer, C.; Polímeros 2013, 23, 451.

19. Das, B.; Konwar, U.; Mandal, M.; Karak, N.; Ind. Crops Prod. 2013, 44, 396.

20. Thakur, S.; Karak, N.; Prog. Org. Coatings 2013, 76, 157.

21. Valero, M. F.; Gonzalez, A.; J. Elastomers Plast. 2012, 44, 433.

22. Miléo, P. C.; Mulinari, D. R.; Baptista, C. R. P.; Rocha, G. J. M.; Gonçalves, R.; Procedia Eng. 2011, 10, 2068.

23. dos Santos, D.; Tavares, L.; Batalha, G.; J. Achiev. Mater. Manuf. Eng. 2012, 54, 211.

24. Wolf, M. T.; Dearth, C. L.; Sonnenberg, S. B.; Loboa, E. G.; Badylak, S. F.; Adv. Drug Deliv. Rev. 2015, 84, 208.

25. Valero, M. F.; Ortegón, Y.; J. Elastomers Plast. 2015, 47, 360.

26. Ortegón, Y.; Tesis de Maestría, Universidad de La Sabana, 2014.

27. Deng, M.; Zhou, J.; Chen, G.; Burkley, D.; Xu, Y.; Jamiolkowski, D.; Barbolt, T.; Biomaterials 2005, 26, 4327.

28. Lyu, S.; Untereker, D.; Int. J. Mol. Sci. 2009, 10, 4033. http://dx.doi. org/10.3390/ijms10094033 
29. Uribe, D.; Giraldo, D.; Gutierrez, S.; Merino, F.; Rev. Peru. Biol. 2010, 17, 133.

30. Ates, B.; Koytepe, S.; Karaaslan, M. G.; Balcioglu, S.; Gulgen, S.; Int. J. Adhes. Adhes. 2014, 49, 90.

31. Kara, F.; Aksoy, E. A.; Yuksekdag, Z.; Hasirci, N.; Aksoy, S.; Carbohydr. Polym. 2014, 112, 39.

32. Pignatello, R.; Impallomeni, G.; Pistarà, V.; Cupri, S.; Graziano, A. C. E.; Cardile, V.; Ballistreri, A.; Mater. Sci. Eng. C 2015, 46, 470.

33. Arnal-Pastor, M.; Comin-Cebrian, S.; Martinez-Ramos, C.; Monleon Pradas, M.; Valles-Lluch, A.; J. Biomater. Appl. 2016, 30, 1429.

34. Bakhshi, H.; Yeganeh, H.; Mehdipour-Ataei, S.; Shokrgozar, M. A.; Yari, A.; Saeedi-Eslami, S. N.; Mater. Sci. Eng. C 2013, 33, 153.

35. Han, W.; Tu, M.; Zeng, R.; Zhao, J.; Zhou, C.; Carbohydr. Polym. 2012, 90, 1353.

36. Calvo-Correas, T.; Santamaria-Echart, A.; Saralegi, A.; Martin, L.; Valea, Á.; Corcuera, M. A.; Eceiza, A.; Eur. Polym. J. 2015, 70, 173.

37. Guan, J.; Sacks, M. S.; Beckman, E. J.; Wagner, W. R.; Biomaterials 2004, $25,85$.

38. Ruan, C.; Hu, N.; Hu, Y.; Jiang, L.; Cai, Q.; Wang, H.; Pan, H.; Lu, W. W.; Wang, Y.; Polymer (Guildf). 2014, 55, 1020.
39. Larraza, Í.; Tesis de Pregrado, Universidad Autónoma de Madrid, 2012.

40. Gogoi, S.; Barua, S.; Karak, N.; Prog. Org. Coatings 2014, 77, 1418.

41. Cherng, J. Y.; Hou, T. Y.; Shih, M. F.; Talsma, H.; Hennink, W. E.; Int. J. Pharm. 2013, 450, 145.

42. Spontón, M.; Casis, N.; Mazo, P.; Raud, B.; Simonetta, A.; Ríos, L.; Estenoz, D.; Int. Biodeterior. Biodegradation 2013, 85, 85.

43. Kara, F.; Aksoy, E. A.; Yuksekdag, Z.; Aksoy, S.; Hasirci, N.; Appl. Surf. Sci. 2015, 357, 1692.

44. Tijing, L. D.; Ruelo, M. T. G.; Amarjargal, A.; Pant, H. R.; Park, C. H.; Kim, C. S.; Mater. Chem. Phys. 2012, 134, 557.

45. Clauss, M.; Trampuz, A.; Borens, O.; Bohner, M.; Ilchmann, T.; Acta Biomater. 2010, 6, 3791.

46. Reddy, T. T.; Kano, A.; Maruyama, A.; Takahara, A.; J. Biomater. Sci. Polym. Ed. 2010, 21, 1483.

47. Giannitelli, S. M.; Basoli, F.; Mozetic, P.; Piva, P.; Bartuli, F. N.; Luciani, F.; Arcuri, C.; Trombetta, M.; Rainer, A.; Licoccia, S.; Mater. Sci. Eng. C. Mater. Biol. Appl. 2015, 51, 329. 